\title{
KEANEKARAGAMAN SERANGGA PENGUNJUNG TANAMAN CABAI RAWIT (Capsicum annuum L.) DI WIYORO, BANTUL
}

\author{
Ichsan Luqmana Indra Putra ${ }^{1}$, Listiatie Budi Utami ${ }^{2}$ \\ 1,2 Prodi Biologi, Universitas Ahmad Dahlan, Jl. Ringroad Selatan, Kragilan, Tamanan, Kec. \\ Banguntapan, Bantul, Daerah Istimewa Yogyakarta, \\ 1.
}

\begin{abstract}
Chili is one of the plants that's planted Indonesian. Excessive use of chemical insecticides in chili planters can cause damage to ecosystems for example reducing in biodiversity. This study aims to determine the diversity and abundance of insects found in chili plants in Banguntapan, Bantul. Sampling uses indirect capture, insect nets, yellow pan traps (YPT), and pitfalls. Insect nets were swung along vertically in chili beds. 15 pieces of YPT and pitfalls were installed for each trap. Sampling was done 8 times in 2 months. The results of this research showed that order that had most species was Hymenoptera (83 species), while the least were Blattaria, Dermaptera, Diplura, Strepsiptera, and Trombidiformes, each 1 species. The order that has the most abundance individuals was Diptera with 2939 individuals. The species that has the highest abundance was Paratrechina longicornis (Hym: Formicidae) with 1071 individuals. The Shanon-Wiener Index value obtained is 1.883621, which classified as medium diversity.
\end{abstract}

Keywords: Capsicum annuum, Diptera, Hymenoptera, Paratrechina longicornis, Shanon-Wiener

\begin{abstract}
Abstrak
Cabai merupakan salah satu tanaman yang banyak ditanam oleh masyarakat di Indonesia karena merupakan salah satu bahan masakan yang penting bagi mayoritas warga Indonesia. Persaingan yang terjadi antara para pedagang cabai menyebabkan penanggulangan hama masih sangat bergantung dengan insektisida kimia. Penggunaan insektisida kimia secara berlebihan dapat menyebakan rusaknya ekosistem, salah satunya adalah berkurangnya keanekaragaman hayati. Penelitian ini bertujuan untuk mengetahui keanekaragaman dan kelimpahan Serangga yang terdapat pada tanaman cabai di Banguntapan, Bantul. Pengambilan sampel menggunakan penangkapan tidak langsung, yaitu dengan jaring serangga, nampan kuning, dan pitfall. Jaring serangga diayunkan sepanjang bedengan tanaman cabai secara vertical. Pemasangan nampan kuning dan pitfall dipasang sebanyak 15 buah untuk masingmasing jebakan. Pengambilan sampel dilakukan sebanyak $8 x$ dalam 2 bulan, sehingga dalam seminggu sekali dilakukan pengambilan sampel di lapang. Hasil penelitian menunjukkan bahwa prdo yang memiliki paling banyak spesies adalah Hymenoptera dengan 83 spesies, sedangkan yang paling sedikit adalah Blattaria, Dermaptera, Diplura, Strepsiptera, dan Trombidiformes, masing-masing dengan 1 spesies. Ordo yang memiliki kelimpahan individu paling banyak adalah Diptera dengan 2939 individu. Spesies yang memiliki kelimpahan tertinggi adalah Paratrechina longicornis (Hym.: Formicidae) dengan 1071 individu. Nilai Indeks Shanon-Wiener yang didapatkan sebesar 1,883621 yang tergolong keanekaragaman sedang.
\end{abstract}

Kata Kunci: Capsicum annuum, Diptera, Hymenoptera, Paratrechina longicornis, Shanon-Wiener

\section{PENDAHULUAN}

Indonesia merupakan negara agraris dengan salah satu sektor penting yaitu bidang pertanian. Salah satu tanaman yang banyak dibudidayakan oleh masyarakat aalah tanaman cabai (capsicum annuum L.). Cabai banyak ditanam oleh warga Indonesia karena dapat memberikan sensasi pedas dan merupakan salah satu bahan utama dalam beberapa masakan khas Indonesia. Banyaknya warga yang masih gemar menanam cabai menjadikan persaingan ekonomi para pedagang cabai semakin tinggi. Dikarenakan tingginya persaingan ekonomi, maka perawatan tanaman masih sangat bergantung pada produk berbahan dasar kimia (Pimentel et. al., 1993). Salah satu 
metode dalam perawatan tanaman yang masih sangat bergantung dengan produk berbasis kimia adalah penanggulangan hama (Wojciechowska et. al., 2016). Dampak dari pestisida kimia sangat besar, baik bagi lingkungan (Groner \& Relyea, 2011) ataupun manusia (Hidayah, 2017). Salah satu dampak yang dapat ditimbulkan adalah berkurangnya keanekaragaman hayati, terutama Serangga (Ndakidemi et. al., 2016). Tujuan dari penelitian ini adalah untuk menghitung dan menginventarisasi serangga yang terdapat pada tanaman cabai, khususnya di Desa Wiyoro, Kecamatan Banguntapan, Bantul. Selain itu, penelitian ini juga bertujuan untuk mengelompokkan serangga yang didapat berdasarkan fungsi ekologisnya. Hipotesis yang dapat diambil dari penelitian ini adalah dengan masih seringnya penggunaan insektisida berbahan dasar kimia pada petani sekitar, maka jenis serangga yang didapatkan tidak terlalu banyak dan Indeks Shannon Wiener yang didapat juga tidak akan tinggi.

\section{METODE PENELITIAN}

Penelitian ini dilaksanakan di kebun cabai Desa Wiyoro, Kecamatan Banguntapan, Bantul. Penelitian dimulai pada Bulan Mei sampai dengan Juni 2019. Identifikasi sampel dilakukan di Laboratorium Terpadu Biologi, Universitas Ahmad Dahlan.

Pengambilan sampel dengan metode plot, dimana plot berukuran 1,5x1,5 m dan tersebar secara acak di area pengambilam sampel. Pada setiap plot dilakukan penangkapan serangga dengan metode tidak langsung yang berupa jaring serangga, nampan kuning, dan pitfall. Pemasangan jebakan dilakukan pada pahi hari (pukul 07.00 WIB) dan diambil pada sore hari (pukul 15.30 WIB). Penggunaan jaring serangga diayunkan di sepanjang bedengan tanaman cabai sambil berjalan. Ayunan dilakukan secara vertical (atas dan bawah). Pada setiap plot diletakkan masing-masing 1 jebakan nampan kuning dan pitfall. Pada kedua jebakan diisi oleh larutan detergen dengan perbandingan air dan detergen 1:2. Jebakan nampan kuning diletakkan pada daerah terbuka sehingga serangga tertarik terhadap warna kuningnya sedangkan pitfall dipasang dengan cara dipendam dengan mulut gelas sejajar dengan permukaan tanah. Serangga yang didapat dari ketiga jebakan tersebut kemudian dicuci dengan akuades dan dipindahkan ke dalam botol berisi alcohol 70\% untuk kemudian diidentifikasi lebih lanjut.

Perhitungan analisis data yang dilakukan adalah dengan menghitung Indeks Keanekaragaman. Indeks Keanekaragaman yang digunakan adalah Indeks Keanekaragaman Shannon-Wiener. Perhitungan Indeks Keanekaragaman dengan menggunakan rumus ShannonWiener menurut Magurran (1998):

$$
\mathrm{H}^{\prime}=-\sum_{i=1}^{a} p_{i}\left(\ln p_{i}\right)
$$

Keterangan : $\mathrm{H}^{\prime}=$ indeks

$$
\begin{aligned}
& \text { pi = proporsi spesies ke-i } \\
& \text { dalam komunitas } \\
& \mathrm{a}=\text { jumlah morfospesies }
\end{aligned}
$$

Pengelompokan serangga berdasarkan fungsi ekologisnya dilakukan setelah proses identifikasi dilaksanakan. Serangga yang sudah teridentifikasi kemudian ditelusuri fungsi ekologisnya berdasarkan literature, baik berupa buku ataupun jurnal terkait.

\section{HASIL PENELITIAN DAN PEMBAHASAN}

\section{Keanekaragaman Serangga pada Tanaman Cabai}

Nilai indeks keanekaragaman dan kemerataan serangga yang didapat menunjukkan nilai Indek keanekaragaman yang tergolong sedang. Kemerataan serangga yang terdapat di lokasi penelitian sendiri tergolong cukup merata karena nilainya masih mendekati 1.00 (Tabel 1). Hasil menunjukkan bahwa nilai Indeks ShannonWiener di pertanaman cabai sebesar 1.88 dan Nilai Indeks Simpson sebesar 0.78 
Tabel 1. Nilai indeks Shannon-Wiener (H) dan indeks Simpson (D) serangga pengunjung tanaman cabai Capsicum annuum L. di Banguntapan, Bantul

\begin{tabular}{lll}
\hline Sampling & H & D \\
\hline Sampling 1 & $\mathbf{1 . 4 1 0 8 7 5}$ & $\mathbf{0 . 6 7 9}$ \\
Sampling 2 & 2.16675 & 0.824 \\
Sampling 3 & $\mathbf{2 . 2 1 9 6 2 5}$ & $\mathbf{0 . 8 4 7}$ \\
Sampling 4 & 2.158125 & 0.84025 \\
Sampling 5 & 1.918875 & 0.768 \\
Sampling 6 & 1.817714 & 0.782 \\
Sampling 7 & 1.4275 & 0.733429 \\
Sampling 8 & 1.9495 & 0.769875 \\
\hline RERATA & $\mathbf{1 . 8 8 3 6 2 1}$ & $\mathbf{0 . 7 8 0}$ \\
\hline
\end{tabular}

Hasil yang didapatkan menunjukkan bawa tingkat keanekaragaman dan kemerataan di ekosistem tersebut tidak terlalu tinggi. Hal ini mungkin dikarenakan tidak banyak serangga yang berinteraksi dengan tanaman cabe. Hal ini sesuai dengan penelitian Agwu et. al. (2018) yang hanya menemukan 12 serangga pada tanaman cabai, yang terdiri dari 10 spesies merupakan serangga herbivore dan 2 spesies predator. Penelitian dari Djieto-Lordon et. al. (2014), menemukan 10 spesies serangga hama pada fase sebelum pembungaan dan 7 spesies hama pada saat ase pembungaan. Penelitian lain menemukan 24 spesies parasitoid yang terdapat pada berasosiasi dengan tanaman cabai (Souza et. al., 2019). Sedangkan penelitian lain tentang predator pada tanaman cabai hanya ditemukan 14 famili serangga pada kahan tanpa biopestisida dan 15 famili serangga pada lahan dengan biopestisida (Sanjaya \& Dibiyantoro, 2012). Selain sedikitnya serangga yang berasosiasi dengan tanaman cabai, hal lain yang dapat menyebabkan rendahnya nilai indeks yang didapat dikarenakan sedikitnya vegetasi lantai yang berada pada lokasi penelitian. Hal ini menyebabkan serangga yang berada baik pada pertanaman cabai ataupun sekitar pertanaman cabai tidak memiliki inang alternatif. Baik inang (tanaman) untuk berlindung, mencari makan, istirahat, ataupun untuk keperluan lainnya (Xu \& Turlings, 2017; Bala et. al., 2018).

\section{Penelitian}

Kelimpahan Serangga pada Lokasi

Hasil penelitian ini mendapatkan 17 ordo, 108 famili, 221 spesies dan 7999 individu. Terdapat lima ordo yang memiliki kelimpahan dan jumlah spesies lebih banyak dibandingkan ordo lainnya. Lima ordo tersebut adalah Hymenoptera (86 spesies), Diptera (47 spesies), Coleoptera (30 spesies), Hemiptera (23 spesies) dan Orthoptera (10 spesies) (Gambar 1). 


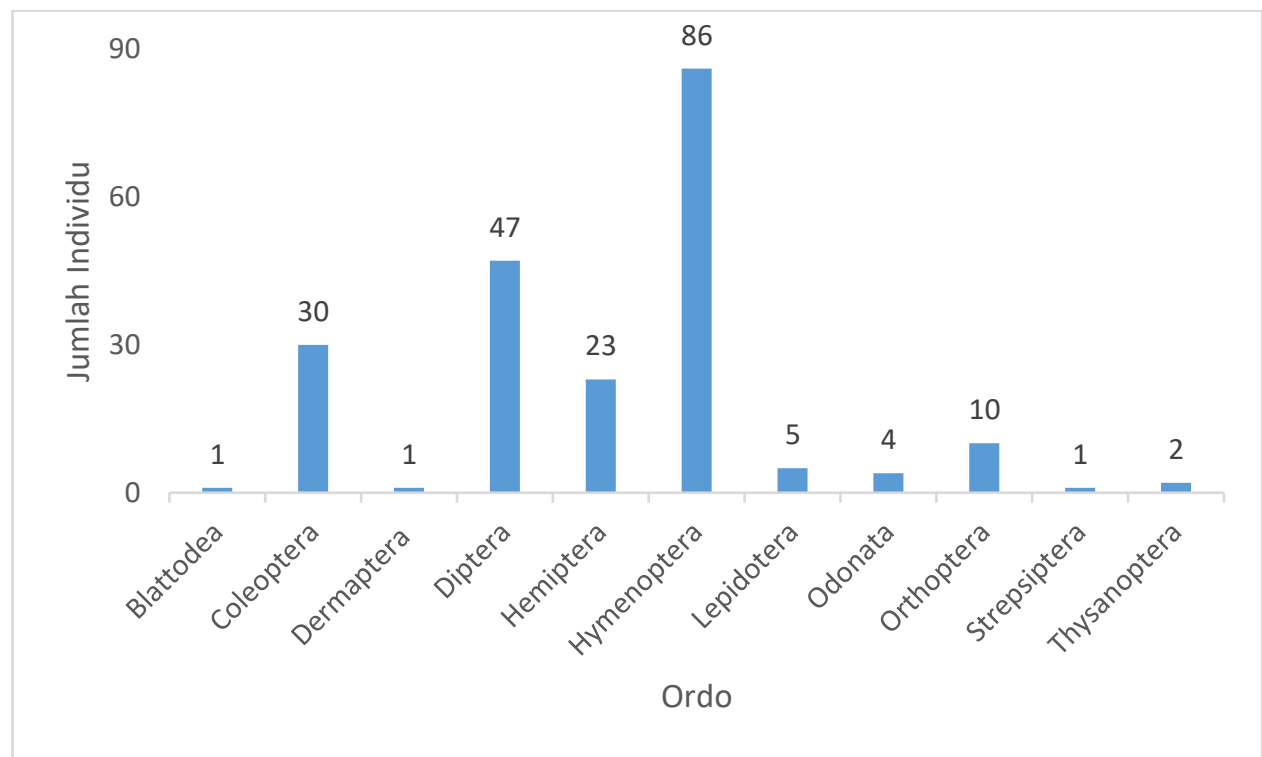

Gambar 1. Jumlah spesies masing-masing ordo yang ditemukan selama penelitian

Hasil yang terlihat memperlihatkan bahwa Hymenoptera merupakan ordo serangga yang paling banyak ditemukan spesiesnya, yaitu sebanyak 86 spesies. Walaupun ditemukan paling banyak spesiesnya, akan tetapi Hymenoptera bukanlah ordo terbesar dalam kelas serangga, melainkan Coleoptera (Borror et. al., 1996). Hal ini dapat disebabkan karena daya jelajah dari Hymenoptera lebih baik daripada Coleoptera (Forbes et. al., 2018). Hampir semua anggota dari Hymenoptera merupakan penjelajah aktif, baik penjelajah melalui aerial maupun terrestrial (Silva et. al., 2014; Jaapar et. al., 2018). Sedangkan untuk Coleoptera biasanya hanya melakukan penerbangan atau penjelajahan dalam radius yang dekat atau pendek saja (Irmler, 2010; Jensen et. al., 2012). Hal ini yang memungkinkan Hymenoptera ditemukan lebih banyak spesies dibandingkan Coleoptera pada lokasi penelitian.

Walaupun Hymenoptera ditemukan paling banyak spesiesnya, akan tetapi untuk jumlah individu ordo yang ditemukan paling melimpah jumlah individunya adalah Diptera (Gambar 2)

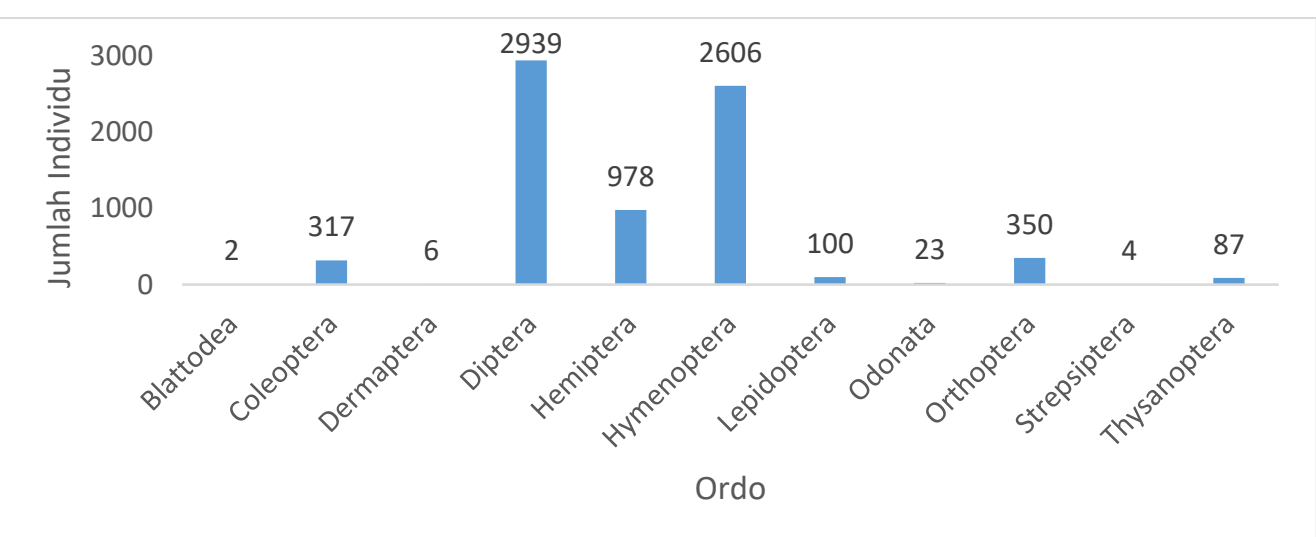

Gambar 2. Jumlah individu masing-masing ordo yang ditemukan selama penelitian

Hal ini mungkin dikarenakan terdapat anggota dari Hymenoptera yang perkembangannya merupakan serangga soliter. Pada Hymenoptera ditemukan adanya parasitoid soliter dimana satu individu parasitoid hanya akan meletakkan satu telur saja pada inangnya (Grissell \& Schauff, 1990).
Lain halnya dengan anggota dari Ordo Diptera yang ditemukan tidak ada yang merupakan serangga dengan perkembangan soliter, dimana satu induk dapat menelurkan lebih dari satu telur pada inangnya (Borror et. al., 1996). 


\section{Fungsi Ekologi Serangga yang Ditemukan}

Hasil dari penelitian ini mendapatkan

5 fungsi ekologi dari serangga yang ditemukan, yaitu herbivor, detritivor, parasitoid, polinator dan predator. Jumlah individu paling tinggi ditemukan pada fungsi detritivor yaitu sebanyak 2994 ekor (Gambar
3), sedangkan yang paling rendah adalah polinator (26 ekor). Apabila dilihat dari jumlah spesies, fungsi yang paling banyak ditemukan jumlah spesiesnya adalah parasitoid sebanyak 75 spesies, sedangkan paling sedikit adalah polinator dengan 4 spesies.

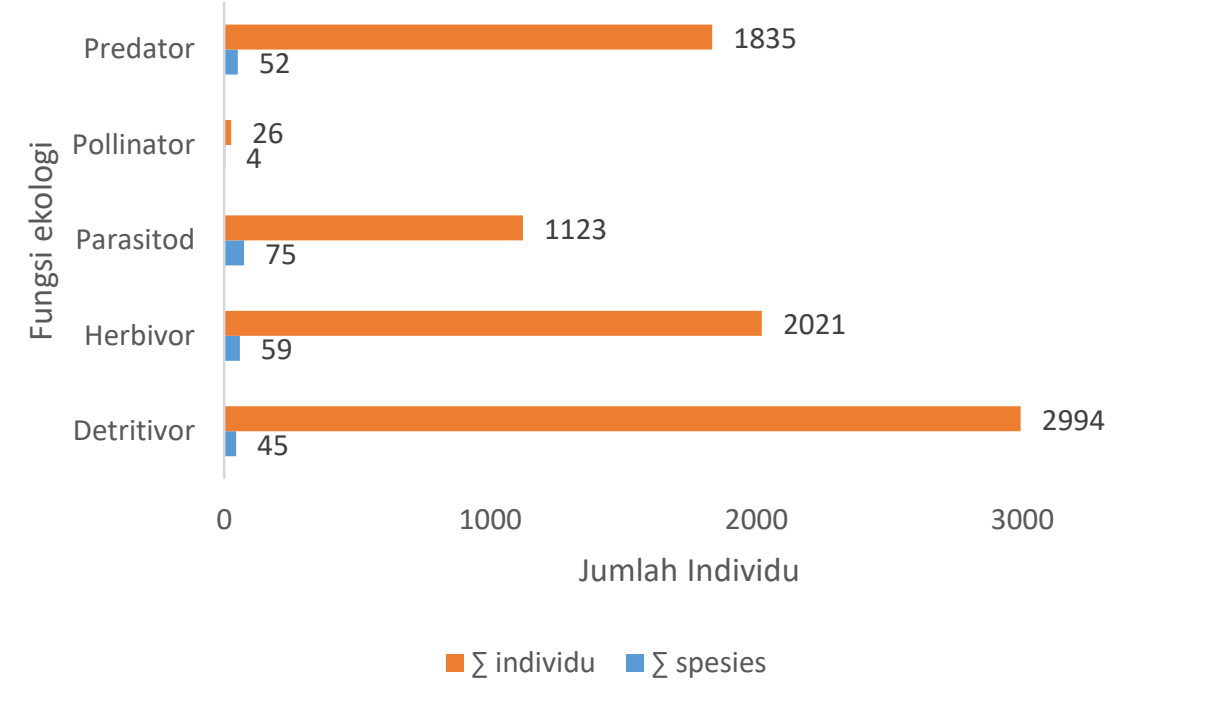

Gambar 3. Jumlah individu dan spesies dari masing-masing fungsi ekologi serangga yang ditemukan

Menurut Hadi dan Aminah (2012), fungsi ekologi serangga yang didapatkan pada suatu ekosistem biasanya hanya sedikit dan yang paling banyak ditemukan adalah peran serangga sebagai herbivor. Hal ini berbeda dengan hasil yang didapatkan pada penelitian ini dimana fungsi detritivor lebih tinggi dibandingkan dengan herbivor. Hal ini mungkin dikarenakan banyaknya material organik yang terdapat pada lokasi penelitian sehingga serangga detritivor dapat lebih baik dan lebih cepat dalam berkembang biaknya. Akan tetapi apabila dilihat dari jumlah spesies, fungsi sebagai herbivor lebih tinggi dari pada detritivor. Menurut Borror et. al. (1996), serangga herbivor memiliki jumlah speseis yang lebih banyak dibandingkan dengan spesies dari serangga detritivor. Selain itu, banyaknya jenis tanaman yang tersedia di lokasi penelitian selain tanaman utama (cabai rawit merah), seperti timun, kacang panjang, padi sawah dan gulma, akan menyebabkan semakin banyak juga spesies dari serangga herbivor yang terdapat dalam lokasi penelitian. Akan tetapi walaupun biasanya ditemuakn dalam jumlah sedikit, serangga detritivor memiliki peran penting dalam suatu ekosistem karena berkaitan dengan ketersediaan unsur hara dalam tanah sebagai penunjang kelangsungan hidup tanaman yang terdapat dalam ekosistem tersebut (Jankielshon, 2018; Bellamy et. al., 2018).

Fungsi ekologi lain yang memiliki jumlah tertinggi tapi dari julah spesies yang didapatkan adalah parasitoid, yaitu sebanyak 75 spesies. Walaupun memiliki jumlah spesies paling banyak, akan tetapi dari jumlah individu masih kalah dengan jumlah individu dari serangga detritivor dan herbivor. Hal ini mungkin dikarenakan terdapat parasitoid yang bersifat soliter, sehingga satu individu parasitoid hanya akan meletakkan satu telur saja pada inangnya. Selain itu, terdapat juga fenomena autoparasitisme, superparasitisme, dan hyperparasitisme pada parasitoid yang dapat menyebabkan menurunnya jumlah individu parasitoid pada suatu ekosistem (Schooler et. al., 2011; Zang et. al., 2011). Ketiga fenomena tersebut menyebabkan serangga parasitoid berkurang jumlah individunya dikarenakan parasitisasi pada parasitoid lain ataupun pada jenisnya sendiri, sehigga menimbulkan adanya kompetisi untuk menggunakan inang sebagai sumber daya kehidupan larva dari parasitoid tersebut (Devescovi et. al., 2017; Abram et. al., 2019). Hal lain yang menyebabkan sedikitnya parasitoid yang ditemukan mungkin dikarenakan banyaknya tanaman yang berbatasan langsung dengan tanaman cabai pada lokasi penelitian. Banyaknya tanaman 
yang berbatasan langsung dengan tanaman cabai akan menyebabkan serangga herbivore tidak hanya akan menetap pada lahan cabai saja, akan tetapi dapat berpindah menuju tanaman lain yang berada di sekitar lahan pertanaman cabai tersebut. Semakin banyak tanaman inang yang tersedia bagi serangga herbivore, maka akan dapat menyebabkan tersebarnya serangga herbivore pada lahan sekitar (Welti et. al., 2017; Liebhold et. al., 2018)

\section{SIMPULAN DAN SARAN}

Kesimpulan yang didapatkan dari penelitian ini adalah, nilai Indeks ShannonWiener yang didapatkan menunjukkan bahwa tingkat keanekaragaman serangga pengunjung tanaman cabai di Desa Wiyoro, Kecamatan Banguntapan, Bantul tergolong sedang. Ordo serangga yang ditemukan berjumlah 17 ordo, dengan ordo yang paling banyak ditemukan spesiesnya adalah Hymenoptera, sedangkan ordo yang paling banyak ditemukan jumlah individunya adalah Diptera. Terdapat 5 fungsi ekologi dari serangga yang ditemukan pada lokasi penelitian, dengan fungsi ekologi sebagai detritivor ditemukan paling melimpah.

Saran yang dapat diberikan adalah perlu adanya penelitian pada musim yang berbeda, sehingga dapat dilihat apakah serangga yag ditemukan akan berbeda atau tidak. Selain itu, perlu adanya inventarisasi penyakit yang ada sehingga dapat dilihat apakah serangga yang didapatkan merupakan serangga penyebab penyakit yang terdapat pada lokasi penelitian.

\section{UCAPAN TERIMAKASIH}

Ucapan terimaksih penulis tujukan kepada Lembaga Penelitian dan Pengabdian Masyarakat (LPPM) UAD yang telah memberikan dana penelitian sehingga penelitia dapat melaksanakan penelitian ini. Penelitia juga mengucapkan terimakasih kepada Saudara Dolfinus yang telah membantu selama proses peneltiian di lapangan.

\section{DAFTAR PUSTAKA}

Abram, P. K., Brodeur, J., Urbaneja, A., \& Tena, A. (2018). Nonreproductive Effects of
Insect Parasitoids on Their Hosts. Annual Review of Entomology, 64(1), 259-276.

https://doi.org/10.1146/annurev-ento011118-111753

Bellamy, A. S., Svensson, O., van den Brink, P. J., Gunnarsson, J., \& Tedengren, M. (2018). Insect community composition and functional roles along a tropical agricultural production gradient. Environmental Science and Pollution Research, 25(14), 13426-13438. https://doi.org/10.1007/s11356-0181818-4

Choate, P. M. (1999). Introduction to the Identification of Beetles (Coleoptera). North, 23-33.

Classen, A. T., DeMarco, J., Hart, S. C., Whitham, T. G., Cobb, N. S., \& Koch, G. W. (2006). Impacts of herbivorous insects on decomposer communities during the early stages of primary succession in a semi-arid woodland. Soil Biology and Biochemistry, 38(5), 972-982. https://doi.org/10.1016/j.soilbio.2005. 08.009

Devescovi, F., Bachmann, G. E., Nussenbaum, A. L., Viscarret, M. M., Cladera, J. L., \& Segura, D. F. (2017). Effects of superparasitism on immature and adult stages of Diachasmimorpha longicaudata Ashmead (Hymenoptera: Braconidae) reared on Ceratitis capitata Wiedemann (Diptera: Tephritidae). Bulletin of Entomological Research, (April), 1-12. https://doi.org/10.1017/S0007485317 00027X

Djieto-Lordon, C., Heumou, C., Elono Azang, P., Alene, C., Ngueng, A., \& Ngassam, P. (2014). Assessment of pest insects of Capsicum annuum L.1753 (Solanaceae) in a cultivation cycle in Yaoundé. International Journal of Biological and Chemical Sciences, 8(2), 621. https://doi.org/10.4314/ijbcs.v8i2.20

Ekenma, J. A., Gregory, E. O., Felicia, E., Gerald, N. A., Michael, U., \& Chukwuemeka, E. (2018). A survey of the insect pests and farmers practices in the cropping of yellow pepper Capsicum annuum Linnaeus in Enugu State of Eastern 
Nigeria. African Journal of Agricultural Research, 13(15), 742-752. https://doi.org/10.5897/ajar2016.118 34

Feener Jr, D. H., \& Brown, B. V. (2002). Diptera As Parasitoids. Annual Review of Entomology, 42(1), 73-97. https://doi.org/10.1146/annurev.ento. 42.1 .73

Forbes, A. A., Bagley, R. K., Beer, M. A., Hippee, A. C., \& Widmayer, H. A. (2018). Quantifying the unquantifiable: Why Hymenoptera, not Coleoptera, is the most speciose animal order. $B M C$ Ecology, 18(1), 1-11. https://doi.org/10.1186/s12898-0180176-x

Gołębiowski, M. (2016). The use of insecticides to control insect pests. Invertebrate Survival Journal, 13, 210220.

Groner, M. L., \& Relyea, R. A. (2011). A tale of two pesticides: How common insecticides affect aquatic communities. Freshwater Biology, 56(11), 2391-2404. https://doi.org/10.1111/j.13652427.2011.02667.x

Hadi, M., \& Aminah. (2012). Keragaman serangga dan perannya di ekosistem sawah. Jurnal Sains Dan Matematika, Vol. 20, pp. 54-57.

Help, C. H. R., Herman, P. M. J., \& Soetaert, K. (1998). Indices of diversity and evenness. Océanis, 24(2459), 61-87.

Hidayah, N. (2017). Pengaruh Penyuluhan Terhadap Perilaku Masyarakat Tentang Kandungan Dan Dampak Pestisida Pada Sayuran Segar. 2(1), 23-29.

Jaapar, M. F., Jajuli, R., Mispan, M. R., \& Ghani, I. A. (2018). Foraging behavior of stingless bee Heterotrigona itama (Cockerell, 1918) (Hymenoptera: Apidae: Meliponini). AIP Conference Proceedings, 1940(April). https://doi.org/10.1063/1.5027952

Jankielsohn, A. (2018). The Importance of Insects in Agricultural Ecosystems. Advances in Entomology, 06(02), 62-73. https://doi.org/10.4236/ae.2018.6200
6

Jensen, K., Mayntz, D., Toft, S., Clissold, F. J., Hunt, J., Raubenheimer, D., \& Simpson, S. J. (2012). Optimal foraging for specific nutrients in predatory beetles. Proceedings of the Royal Society B: Biological Sciences, 279(1736), 22122218.

https://doi.org/10.1098/rspb.2011.24 10

Lawrence, J. F., Ślipiński, A., Seago, A. E., Thayer, M. K., Newton, A. F., \& Marvaldi, A. E. (2011). Phylogeny of the Coleoptera Based on Morphological Characters of Adults and Larvae. Annales Zoologici, 61(1), 1-217. https://doi.org/10.3161/000345411x5 76725

Ndakidemi, B., Mtei, K., \& Ndakidemi, P. A. (2016). Impacts of Synthetic and Botanical Pesticides on Beneficial Insects. Agricultural Sciences, 07(06), 364-372.

https://doi.org/10.4236/as.2016.7603 8

Oldroyd, H. (1954). Handbooks for the identification of British Insects; Diptera. Royal Entomological Society of London, 9(1), 52. https://doi.org/10.1002/rob

Pimentel, D., McLaughlin, L., Zepp, A., Lakitan, B., Kraus, T., Kleinman, P., ... Selig, G. (1993). Environmental and economic effects of reducing pesticide use in agriculture. Agriculture, Ecosystems and Environment, 46(1-4), 273-288. https://doi.org/10.1016/01678809(93)90030-S

Saeed, R., Razaq, M., \& Hardy, I. C. W. (2015). The importance of alternative host plants as reservoirs of the cotton leaf hopper, Amrasca devastans, and its natural enemies. Journal of Pest Science, 88(3), 517-531. https://doi.org/10.1007/s10340-0140638-7

Sanjaya, Y., \& Dibiyantoro, A. L. H. (2012). ( Capsicum Annuum ) Yang Diberi Pestisida Sintetis Versus Biopestisida Racun Laba-Laba ( Nephila Sp . ). J.HPT Tropika, 12(2), 192-199. 
Silva, A. G., Pinto, R. S., Contrera, F. A. L., Albuquerque, P. M. C., \& Rêgo, M. M. C. (2014). Foraging distance of Melipona subnitida Ducke (Hymenoptera: Apidae). Sociobiology, 61(4), 494-501. https://doi.org/10.13102/sociobiology. v61i4.494-501

Sirot, E., Ploye, H., \& Bernstein, C. (1997). State dependent superparasitism in a solitary parasitoid: Egg load and survival. Behavioral Ecology, 8(2), 226-232. https://doi.org/10.1093/beheco/8.2.2 26

Skuhravá, M., Martinez, M., \& Roques, A. (2010). Diptera. Chapter 10. BioRisk, $4(2)$, 553-602. https://doi.org/10.3897/biorisk.4.53

Souza, I. L., Tomazella, V. B., Santos, A. J. N., Moraes, T., \& Silveira, L. C. P. (2018). Parasitoids diversity in organic Sweet Pepper (Capsicum annuum) associated with Basil (Ocimum basilicum) and Marigold (Tagetes erecta ). Brazilian Journal of Biology, 79(4), 603-611. https://doi.org/10.1590/1519. 6984.185417
Thakur, K. B. A. S. V. S. P. S. (2018). Effect of plant nutrition in insect pest management: A review. Journal of Pharmacognosy and Phytochemistry, 7(4), 2737-2742.

Ulrich, I. (2010). Population size and mobility of Cicindela maritima Dejean, 1822 ( Coleoptera : Carabidae ) 1.1822, 1-6.

Xu, H., \& Turlings, T. C. J. (2018). Plant Volatiles as Mate-Finding Cues for Insects. Trends in Plant Science, 23(2), 100-111.

https://doi.org/10.1016/j.tplants.2017. 11.004

Zang, L. S., Liu, T. X., \& Wan, F. H. (2011). Reevaluation of the value of autoparasitoids in biological control. PLoS ONE, 6(5), 1-8. https://doi.org/10.1371/journal.pone. 0020324 